\title{
Urban Land Surface Temperature Monitoring and Surface Thermal Runoff Pollution Evaluation Using UAV Thermal Remote Sensing Technology
}

\author{
Shanshan $\mathrm{Xu}^{1,2, \dagger}$, Kun Yang ${ }^{2,3}$, Yuanting $\mathrm{Xu}{ }^{1,2, \dagger}$, Yanhui Zhu ${ }^{2,3, *}$, Yi Luo ${ }^{2,3} \mathbb{\oplus}$, Chunxue Shang ${ }^{4}$, Jie Zhang ${ }^{1}$, \\ Yang Zhang ${ }^{1,2}$, Min Gao ${ }^{1,2}$ and Changhao $\mathrm{Wu}^{1,2}$
}

1 School of Information Science and Technology, Yunnan Normal University, Kunming 650500, China; xss_5233@163.com (S.X.); xyt5681@163.com (Y.X.); zhuceyouxiangshiye@163.com (J.Z.); zhangyang@ynnu.edu.cn (Y.Z.); M15125829914@163.com (M.G.); wuchanghaochn@gmail.com (C.W.)

2 The Engineering Research Center of GIS Technology in Western China, Ministry of Education of China, Yunnan Normal University, Kunming 650500, China; yangkun@ynnu.edu.cn (K.Y.); lysist@ynnu.edu.cn (Y.L.)

3 Faculty of Geography, Yunnan Normal University, Kunming 650500, China

4 Dean's Office, Yunnan Normal University, Kunming 650500, China; shangchunxue@ynnu.edu.cn

* Correspondence: igiser@126.com

+ These authors contributed equally to this work and should be considered co-first authors.

Citation: Xu, S.; Yang, K.; Xu, Y.; Zhu, Y.; Luo, Y.; Shang, C.; Zhang, J.; Zhang, Y.; Gao, M.; Wu, C. Urban Land Surface Temperature Monitoring and Surface Thermal Runoff Pollution Evaluation Using UAV Thermal Remote Sensing Technology. Sustainability 2021, 13, 11203. https://doi.org/10.3390/ su132011203

\section{Academic Editors:}

Vincenzo Costanzo and Nyuk Hien Wong

Received: 13 July 2021

Accepted: 13 September 2021

Published: 11 October 2021

Publisher's Note: MDPI stays neutral with regard to jurisdictional claims in published maps and institutional affiliations.

Copyright: (c) 2021 by the authors. Licensee MDPI, Basel, Switzerland. This article is an open access article distributed under the terms and conditions of the Creative Commons Attribution (CC BY) license (https:// creativecommons.org/licenses/by/ $4.0 /)$.

\begin{abstract}
With the continuous advancement of urbanization, the impervious surface expands. Urbanization has changed the structure of the natural land surface and led to the intensification of the urban heat island (UHI) effect. This will affect the surface runoff temperature, which, in turn, will affect the surface water temperature of urban lakes. This study will use UAS TIR (un-manned aerial system thermal infrared radiance) remote sensing and in situ observation technology to monitor the urban space surface temperature and thermal runoff in Kunming, Yunnan, in summer; explore the feasibility of UAS TIR remote sensing to continuously observe urban surface temperature during day and night; and analyze thermal runoff pollution. The results of the study show that the difference between UAS TIR LSTs and in situ LSTs (in situ air temperature $10 \mathrm{~cm}$ above the ground.) varies with the type of land covers. Urban surface thermal runoff has varying degrees of impact on water bodies. Based on the influence of physical factors such as vegetation and buildings and meteorological factors such as solar radiation, the RMSE between UAS LSTs and in situ LSTs varies from 1 to $5{ }^{\circ} \mathrm{C}$. Land cover types such as pervious bricks, asphalt, and cement usually show higher RMSE values. Before and after rainfall, the in situ data of the lake surface water temperature (LSWT) showed a phenomenon of first falling and then rising. The linear regression analysis results show that the $\mathrm{R}^{2}$ of the daytime model is 0.92 , which has high consistency; the average $\mathrm{R}^{2}$ at night is 0.38 ; the averages $\mathrm{R}^{2}$ before and after rainfall are 0.50 and 0.83 , respectively; and the average RMSE is $1.94{ }^{\circ} \mathrm{C}$. Observational data shows that thermal runoff quickly reaches thermal equilibrium with the land surface temperature about $30 \mathrm{~min}$ after rainfall. The thermal runoff around the lake has a certain warming effect on LSWT.
\end{abstract}

Keywords: urban heat island; UAS TIR; remote sensing; land covers; thermal runoff; LSWT

\section{Introduction}

Urbanization [1] is the most important process of human activities since the 20th century [2], and the impervious surface shows a tendency of rapid expansion. The impervious surface [3] is mainly composed of urban roads, parking lots, city squares, building roofs, and other infrastructure. It has a low permeability coefficient, which prevents surface water from infiltrating or soaking into the ground, resulting in large areas of accumulation during the flood and rainy seasons. Accumulation water causes regional waterlogging in cities, which, in turn, forms the phenomenon of urban rain islands [3]. The United States once set up a dense rainfall observation network in St. Louis, Missouri, and its 
nearby suburbs [4] for 5 years of observational research, which confirmed that the city and its downwind direction do experience the "rain island effect". In addition, impervious surfaces also exhibit the characteristics of high heat absorption [5], causing the urban heat island (UHI) effect. UHI will cause a series of environmental changes, such as regional climate, vegetation growth, and water and air quality [6]. Today, more than 55\% of the world's population now live in urban areas, a proportion that is expected to increase to $68 \%$ by 2050 [7]. With climate warming [8] and the world's rapid urbanization, UHI and related consequences are expected to be more serious. This is especially true for developing countries (particularly China and India), which are expected to account for $35 \%$ of the global urban population growth between 2018 and 2050 [9]. In the past decades, many scholars have found that the increase of impervious surfaces is the main cause of heat islands and rain islands [10]. The observation of urban surface temperature and impervious surface through satellite sensors is the main source of research data [11]. Among high-latitude lakes, shallow lakes respond faster to meteorological factors than deep-water lakes [12]. Remote sensing offers an important means of detecting and analyzing surface temperature changes. This includes satellite sensors such as ASTER, MODIS, and Landsat, which can capture surface temperature with a spatial resolution of $30 \mathrm{~m}$ to $1 \mathrm{~km} \mathrm{[13-16].} \mathrm{However,} \mathrm{the}$ revisit period of these satellite sensors is long, resulting in low time resolution of remote sensing image data [17]. Therefore, these methods are not sufficient to assess changes in urban surface temperature throughout the day or to capture the spatial heterogeneity of urban surface temperature on a small scale.

The rapid development of unmanned aerial system (UAS) technology in recent years seems to be able to make up for the lack of satellite remote sensing technology [18-21]. UAS carrying visible light lenses were used to observe night lights in local areas of the city [20]. UAS remote sensing technology is used to carry out surface temperature observations in complex urban environments [22]. The study found that surface temperature is affected by land cover materials, weather, urban geometry, and traffic characteristics. The threedimensional thermal characteristics of the forest canopy were studied by using UAS remote sensing technology [23]. For the first time, the obtained RGB image and thermal image were combined to generate a three-dimensional structure of separate RGB image and point cloud data. The research results are of great significance to atmospheric, hydrological, and ecological simulations. One study used UAS and satellite data to obtain and analyze the distribution of surface temperature and thermal characteristics in the geothermal area of Tuscany, Italy [24]. Therefore, it can be concluded that UAS remote sensing technology has significant advantages in urban thermal environment assessment.

Suburban areas might experience high flood risk as urbanization develops even though the impact at the whole basin level might be not remarkable [25]. The amount of heat added to the runoff is highly dependent on both the characteristics of the rainfall event and the weather conditions prior to the storm event [26]. In sunny conditions, the land cover of the city absorbs solar radiation, causing the LSTs to rise [27]. In summer, impervious surfaces in urban areas may store large amounts of heat [28]. The impact of climate warming on lake surface water temperature will not change in the short term [29]. There is the most strongly correlated near surface air temperature (NSAT) and lake surface water temperature (LSWT)-day [30]. The authors of [31] show that, when rainfall occurs on a sunny day, the runoff formed on the surface will be heated, and the temperature of runoff will rise significantly. Because urban lakes are the final receiving water body of runoff, the Lake Surface Water Temperature (LSWT) will rise. This process will seriously affect the aquatic communities. It also leads to the deterioration of water quality [31] and the degradation of the cold-water ecosystem [25]. Sabouri et al. [32] found that the average asphalt runoff temperature strongly depends on the initial asphalt temperature at the beginning of the rainfall. Rapid urban development, the expansion of impervious surfaces and global warming are the main causes of LSWT changes [33].

In summary, the use of UAS thermal infrared remote sensing technology to carry out urban thermal environment research has become mature. Compared with satellite remote 
sensing, UAS has a high resolution, which can better reflect the macroscale temperature changes. The increase of various underlying surfaces is the main cause of the heat island and rain island. Therefore, it is very meaningful to monitor the surface temperature and evaluate the pollution of thermal runoff. This study selects typical areas of the city to carry out a demonstration study. It uses UAS to apply thermal infrared and visible light lenses to different land covers in the study area under sunny and rainy conditions for $24 \mathrm{~h}$ of continuous observation; analyzes the temperature change characteristics of different land cover types; reveals the variability of urban surface temperature in different weathers; and evaluates the daily variation and uncertainty of surface temperature. The feasibility of using UAS remote sensing technology to carry out air-to-water heat exchange in urban space is discussed from a macro perspective. It also evaluates in detail the effects of different land cover surfaces on thermal runoff and then on the changes in lake water quality from sunny days and rainfall.

\section{Materials and Methods}

\subsection{Study Area}

This study was conducted in an area of the Yunnan Normal University Campus located in Kunming City, Southwest China. Kunming is the economic development center of Yunnan Province [34]. With the acceleration of construction in South Asia and Southeast Asia, the process of industrialization and urbanization is advancing rapidly. In the past 30 years, those areas have experienced extensive urbanization, and the urban expansion has been significant. This study provides a natural test site [35]. This study selects a representative community in Kunming (Figure 1). The area of the study area is 2,200,000 m², and the altitude is about $1945 \mathrm{~m}$. The study area includes the main land cover types of urban surface space, such as asphalt, concrete, pervious bricks, lawns, and lakes. The location of each land cover surface is distributed as follows: the average depth of Lake 1 and Lake 2 is about $2 \mathrm{~m}$; the area is about $4340 \mathrm{~m}^{2}$ and 15,000 $\mathrm{m}^{2}$; and Lake 3 is about $1 \mathrm{~m}$ with an area of about $6000 \mathrm{~m}^{2}$. Due to the limited battery life of UAS, one flight mission cannot cover the entire study area, so that the study area is divided into three areas for observation.

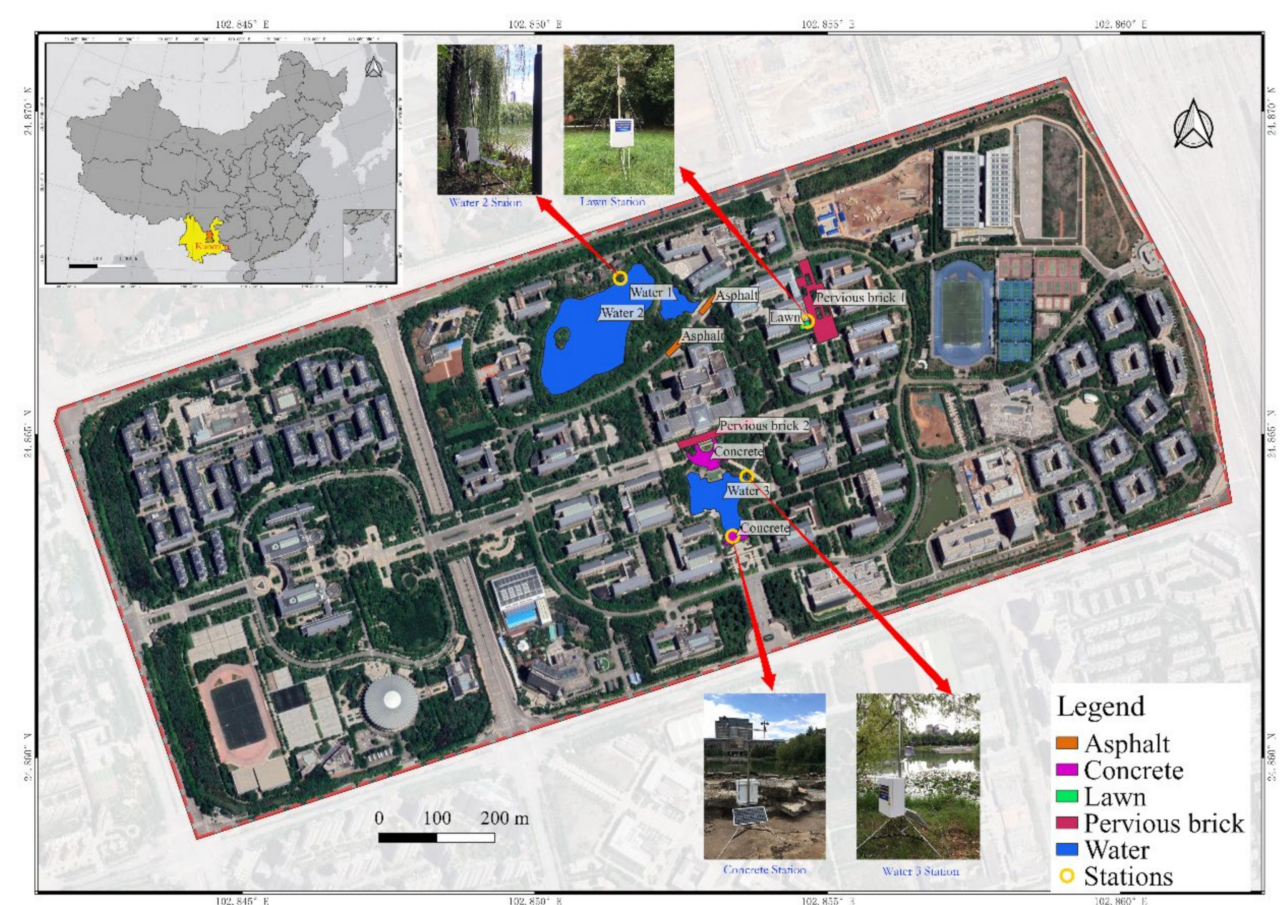

Figure 1. Location map of the study area and images of monitoring site. 


\subsection{Acquisition of UAS Images}

This study selected 24 July 2020, 9:00 a.m., to 25 July 2020, 7:00 a.m. (clear, windy, and little cloud cover); 26 July 2020, 4:00 p.m. to 7:00 p.m. (rainfall); and 2 August 2020 9:00 a.m. to 9:00 p.m. (rainfall). On-site experimental observations were carried out in three time periods in 2020. It was a dubious task to complete the measurement of all three areas at one time, and each set was separated by two hours. (The detailed task time is shown in Supplementary Materials Tables S1-S3). UAS flew 21 times, day and night, regardless of sunny and rainy weather.

The project team used DJI Matrice 210 quadrotor UAS equipped with Zenmuse XT2 thermal infrared camera to obtain thermal infrared images of the study area (spectral range: 7.5-13.5 $\mu \mathrm{m}$, accuracy: $\pm 5^{\circ} \mathrm{C}$, and emissivity: 0.98 ). The relevant equipment parameters are shown in Table S4 (See Supplementary Materials). UAS have a flying speed of $8 \mathrm{~m}-10 \mathrm{~m} / \mathrm{s}$, a flying altitude of $120 \mathrm{~m}-150 \mathrm{~m}$, an image overlap rate of $85 \%$, and a spatial resolution of $10 \mathrm{~cm}$. Emissivity is an important parameter for measuring the LSTs. For the emissivity of different land covers in this study, please refer to Table S5 in the Supplementary Materials.

\subsection{Acquisition of LST In Situ Data}

Considering the land cover types and the measurement time distributed in the study area, a total of 1176 points were selected for in situ measurement. Thermometers were held by hand vertical to the ground and about $10 \mathrm{~cm}$ away from the ground during measurement. We would randomly take seven measurement points for each land cover and take the average value as the in situ data. We would complete a set of measurement tasks every two hours, with each set being completed within $30 \mathrm{~min}$. In addition, we deployed thermal environment monitoring nodes in 4 different areas of the study area. The node obtains atmospheric humidity, atmospheric temperature, LSTs, LSWT, wind speed, wind direction, rainfall, total solar radiation, etc. parameters every 1 min (detailed See Table S6).

\subsection{The Influence of Various Land Cover Types on Surface Thermal Runoff during Rainfall Events}

Due to the in situ measurement, data of the first type of pervious brick and the second type of pervious brick in Figure 2 are different $\left({ }^{\circ} \mathrm{C}\right)$, because, for the purpose of this study, we established that these are two different materials. In order to explore the influence of different land covers on rainfall runoff temperature, we selected two sunny rainfall events (July 26 and August 2) for observation. During these two days of observation, the ground surface was exposed to the sun before the rainfall, storing a lot of heat. When rainfall reaches the ground in such conditions, surface runoff is formed, and intense heat exchange with the ground occurs in a short period of time, which meets the requirements of observation conditions. We analyzed the characteristics of the LSTs change before and after two rainfall events to reveal the impact of different land cover types on surface runoff.

\subsection{Stitching Method of UAS Images}

The images acquired by UAS need to be further stitched. The quality of stitching is related to the flight stability of UAS and the stitching algorithm. Therefore, it is very important to obtain clear images and select a suitable image stitching algorithm. In this study, the method of extracting scale-invariant feature transform (SIFT) feature points was used to register the relationship between images. This method can keep the image scaling, rotation, and affine transformation invariant when describing the local features of the image [36]. The SIFT algorithm is mainly divided into four steps: scale space construction, Gaussian pyramid establishment, extremum detection, and feature point description vector construction. The results of many experiments have shown that the flying height and image overlap rate of UAS will also affect the stitching results. A large number of experiments has verified that setting the flying height of UAS to between 120 and $150 \mathrm{~m}$ and the overlap rate of images to $85 \%$ can achieve the best stitching effect. 


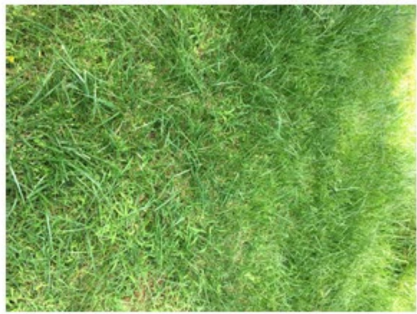

Lawn

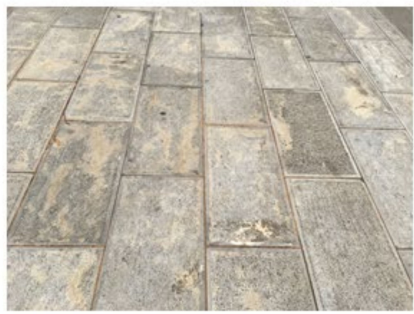

Pervious brick1

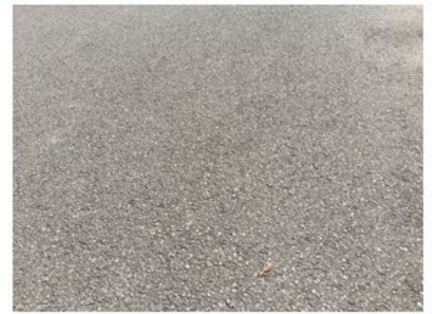

Asphalt

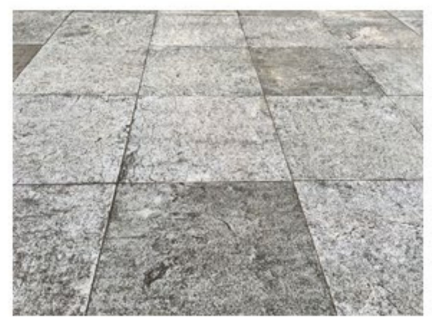

Pervious brick2

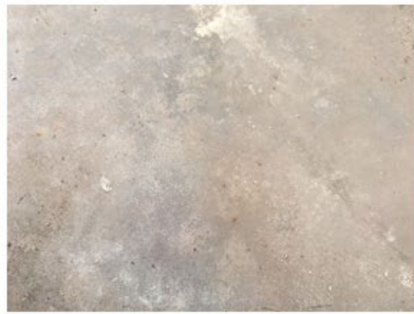

Concrete

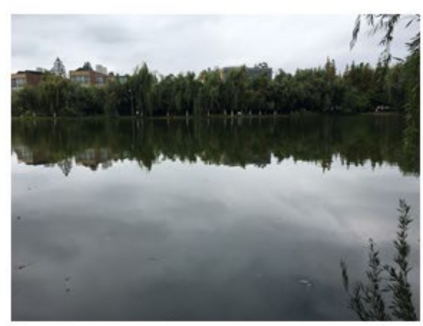

Water surface

Figure 2. Images of land cover types.

\section{Results}

\subsection{LSTs Change Based on UAS Images}

Figure 3 shows the stitching results of thermal infrared images of the study area at 9:12 a.m., 10:58 a.m., and 5:16 p.m. on July 24. The results show that the temperature of trees is lower than that of the lake surface. Due to the oblique effect of the sun, the shadows of surrounding buildings will affect the observation.

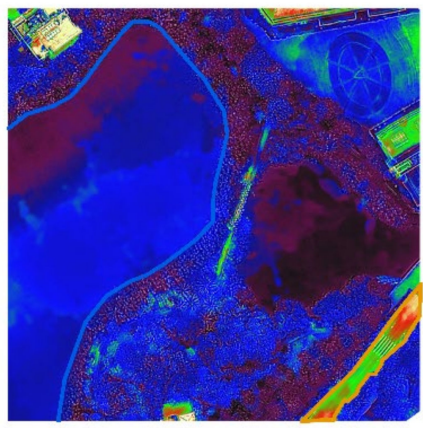

9:12 AM at July 24

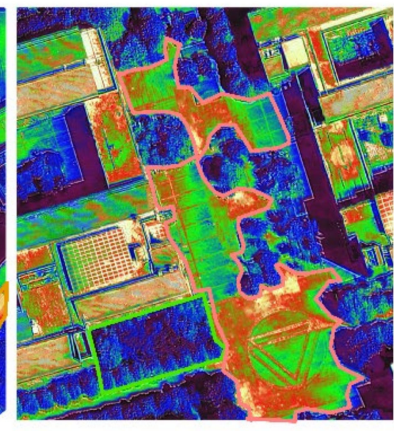

10:58 AM at July 24

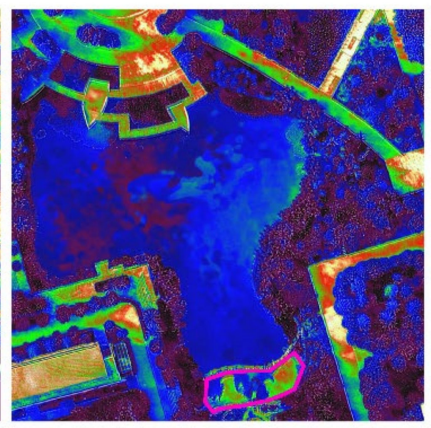

5:16 PM at July 24
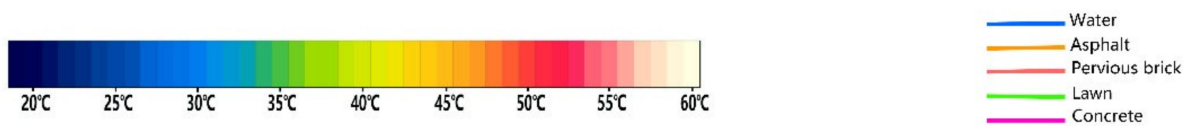

Figure 3. Visual presentation of UAS TIR images.

The image shows that the land cover of the ground quickly absorbs heat and increases at 10:58 a.m. The temperature of the first type of pervious brick changes from $26.0^{\circ} \mathrm{C}$ to $30.7^{\circ} \mathrm{C}$, and the average temperature rise was $4.7^{\circ} \mathrm{C}$. The building roof is the hottest place; it is about ten degrees away from the ground under the shade of the trees, indicating that the vegetation has a good function of reflecting solar radiation, thereby reducing the absorption of ground heat. Figure 3 also shows that the exposed pervious bricks at 10:58 a.m. have some obvious heat shadows. Due to the action of wind, part of the heat on the surface of pervious brick is taken away, resulting in uneven temperature distribution on the ground. The LSTs increased rapidly due to the effect of solar radiation; the highest temperature reached $58.6^{\circ} \mathrm{C}$ at 10:58 a.m. Figures S1-S13 (see Supplementary Materials A) show the thermal infrared images of different land covers from 24 flight missions. Each image corresponds to at least one land cover type. 


\subsection{The Temperature Change Characteristics of Each Land Cover in a Daytime Series}

Figure 4 shows the in situ measurement results and UAS measurement results on July 24. Figure 4 a shows the daytime observation at 3:17 p.m. after UAS underestimated the temperature of the asphalt surface by $5.8^{\circ} \mathrm{C}$ and overestimated the temperature of lawn and water body by $1.2-12.5^{\circ} \mathrm{C}$. UAS observed that various land covers at $12 \mathrm{p} . \mathrm{m}$. and 1 p.m. had relatively small error values. Figure $4 \mathrm{~b}$ shows that the changes in the two observation results of asphalt, concrete, and pervious bricks (two types) observed at nighttime tend to be consistent.
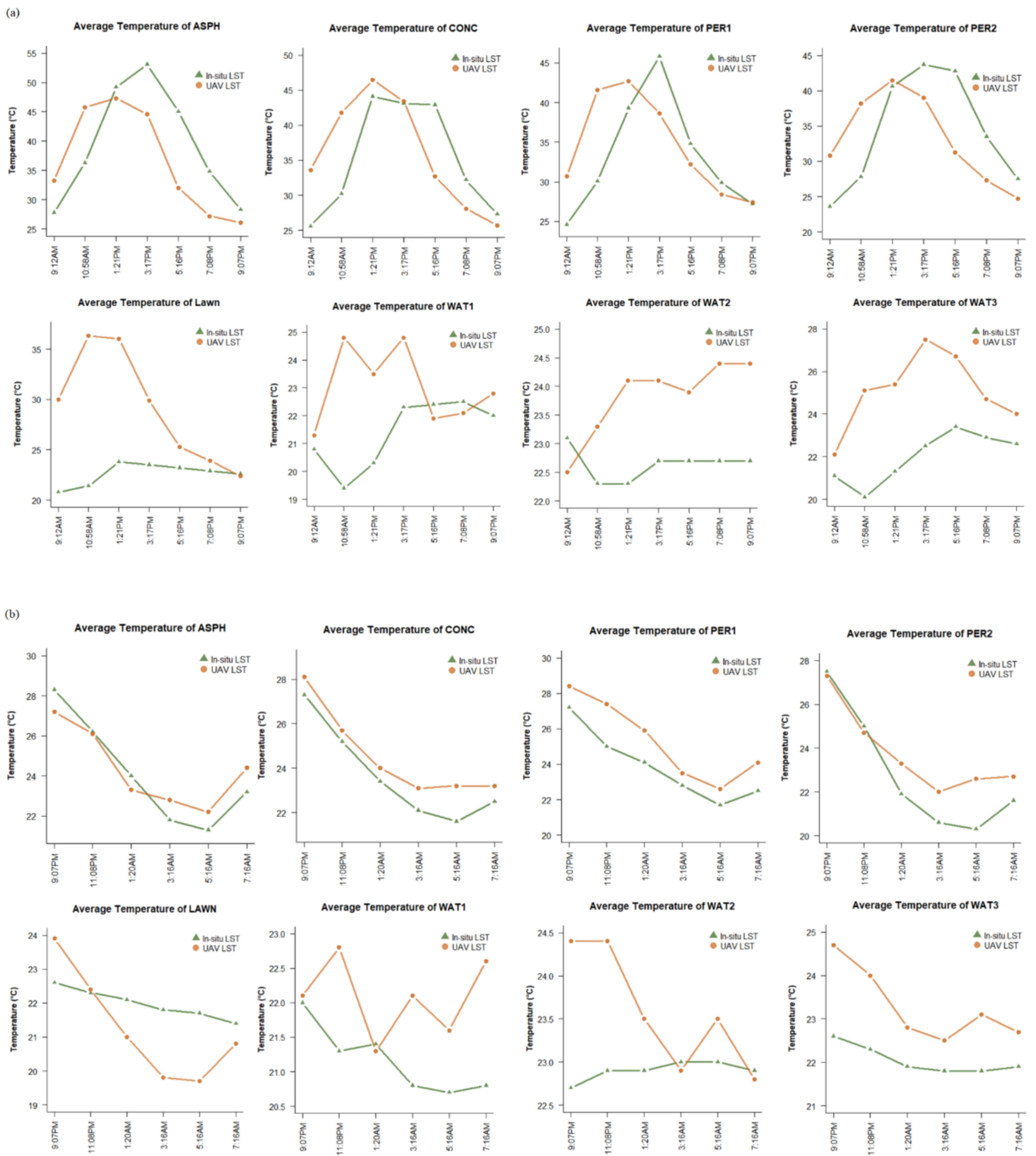

Figure 4. UAS and in situ temperature trends. (a) The daytime temperature trend on July 24. (b) The nighttime temperature trend on July 24. 
Figure 5 shows the in situ observation results and UAS observation results of the land cover types during the day and night on July 24. The results show that, although the two observation methods have certain errors and lags, the two observation results show strong consistency.

(a)

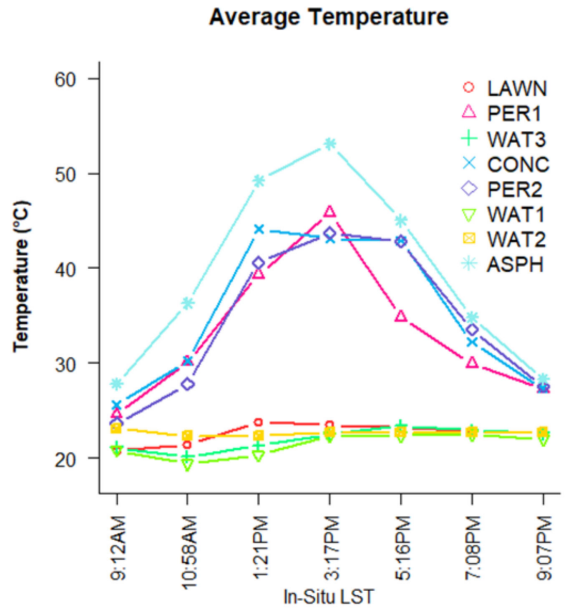

(c)

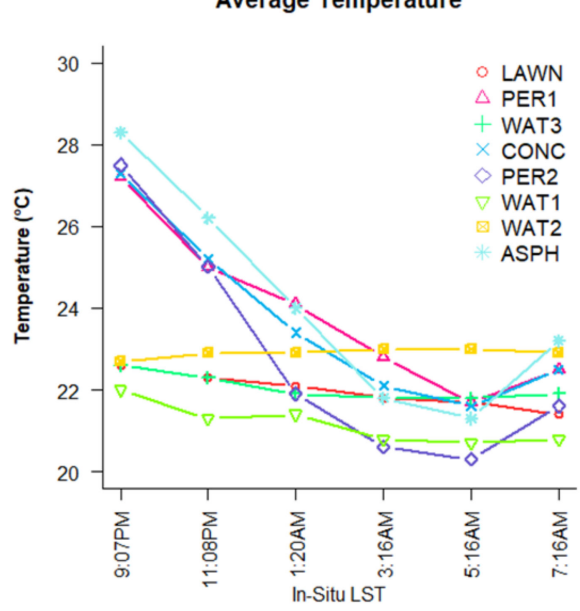

(b)

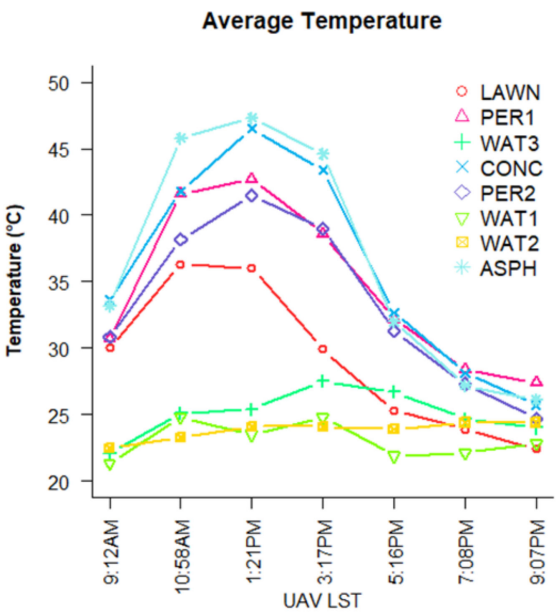

(d)

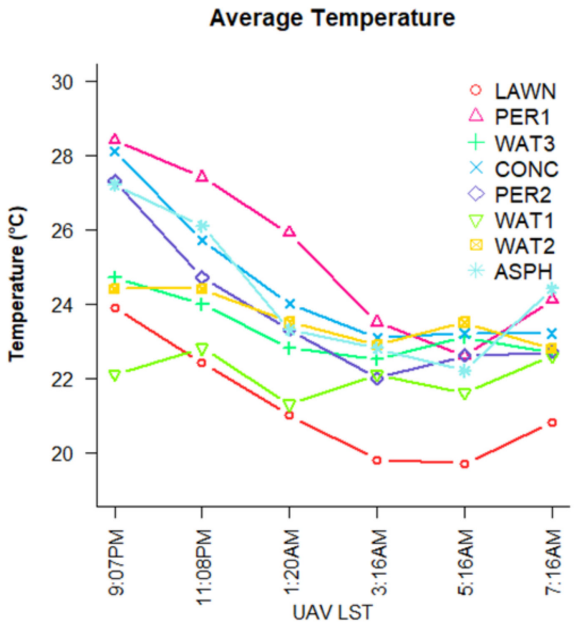

Figure 5. The trend of day and night temperature values of different land covers. (a) Daytime in situ temperature trends of different land covers. (b) Daytime UAS temperature trends of different land covers. (c) Night in situ temperature trends of different land covers. (d) Night UAS temperature trends of different land covers.

Figure 6 shows that the two observation results of asphalt, concrete, and pervious brick land surfaces show a high degree of consistency. Observations of lawn and three lakes indicate that the observed temperature of UAS is relatively high. 

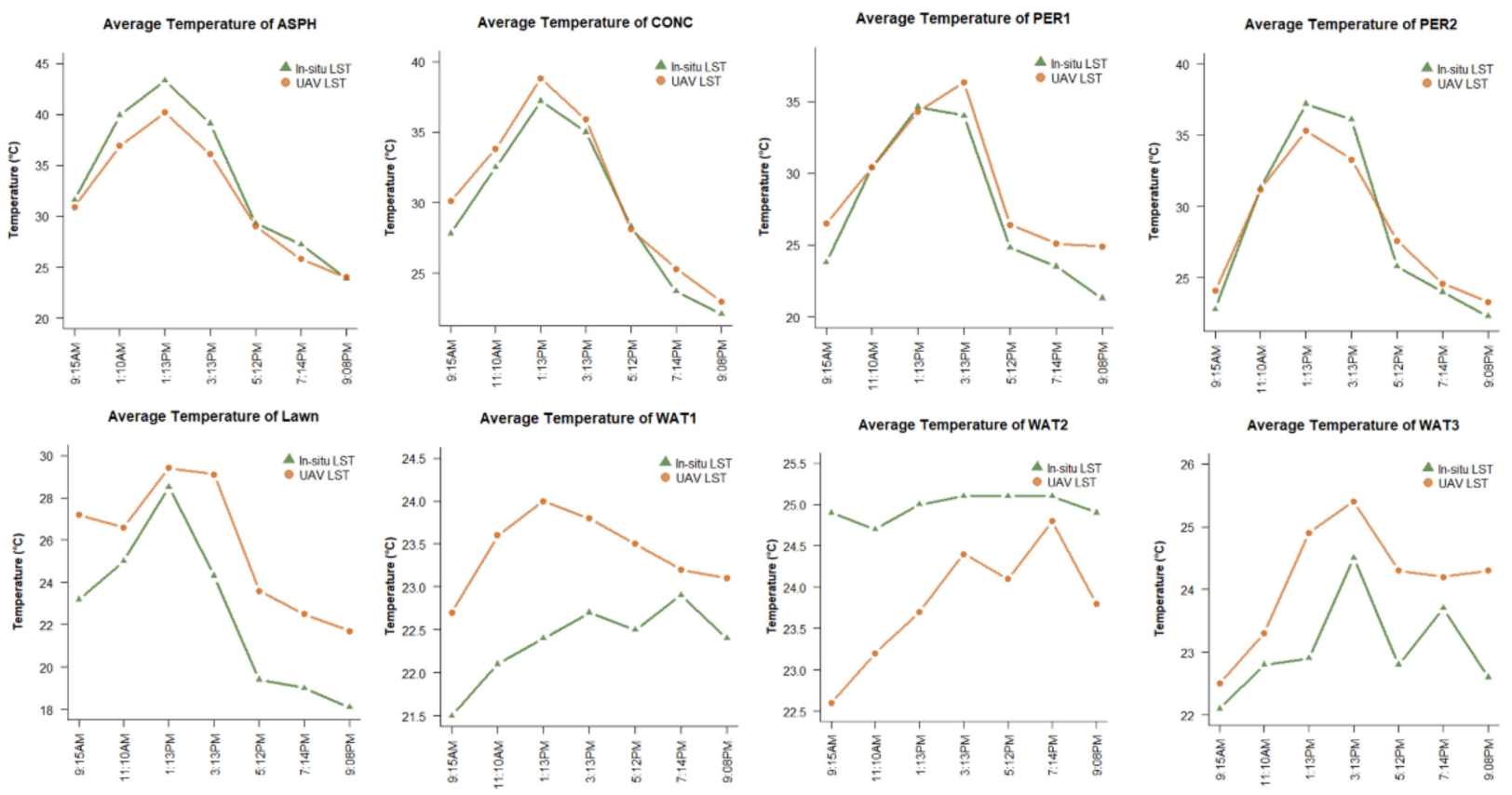

Figure 6. UAS and in situ measured daily temperature trends on August 2.

Since a rainfall event occurred between 3:59 p.m. and 4:40 p.m. on August 2, we used two measurement results to explore the impact of rainfall runoff on lake water temperature. Figure $7 \mathrm{a}$ is the temperature value measured in situ, and Figure $7 \mathrm{~b}$ is the temperature value measured by UAS. The peak value of the data in Figure $7 \mathrm{a}$ is higher than that in Figure $7 \mathrm{~b}$, and, compared with the observed data on July 24 (Figure 5), the overall fluctuation of the data observed by UAS is smaller.

(a)

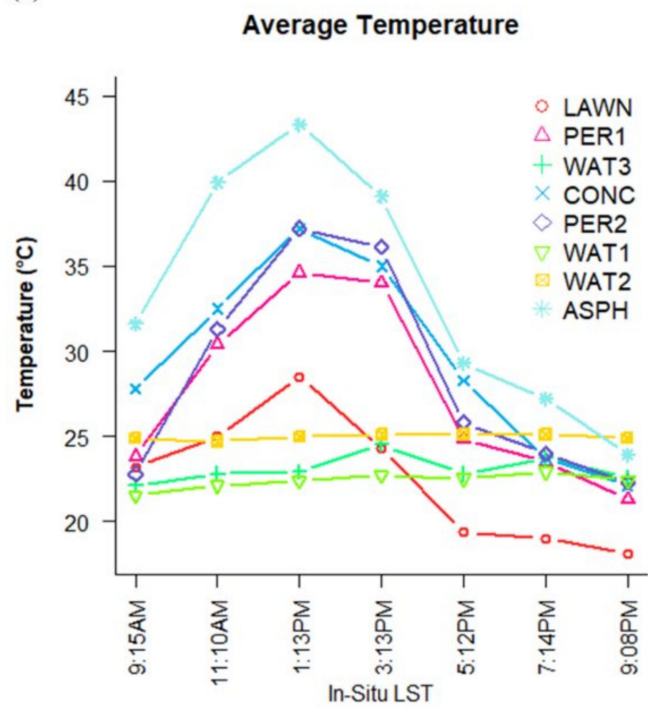

(b)

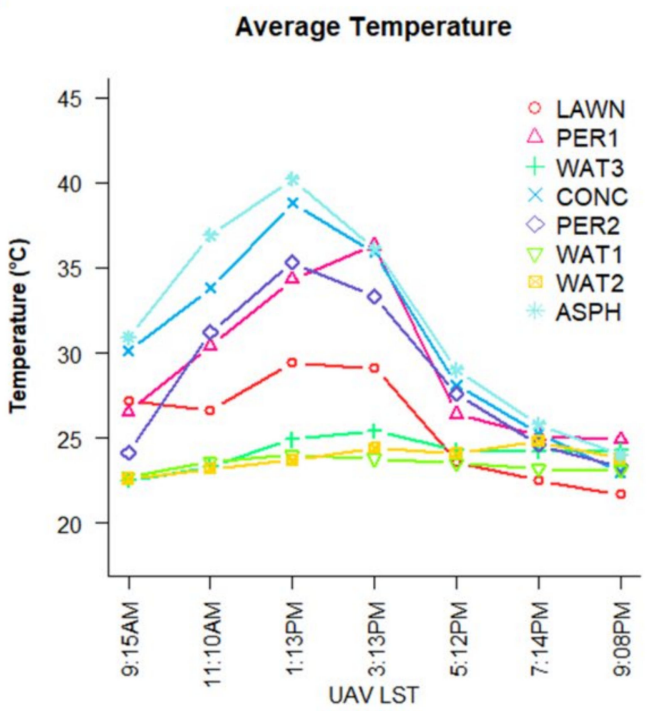

Figure 7. The temperature changes of different land surfaces on August 2. (a) In situ temperature changes of different land surfaces; (b) UAS temperature changes of different land surfaces.

\subsection{The Influence of Different Land Covers on Rainfall Runoff Temperature}

Figure 8 shows the temperature changes of different land surfaces before and after the rainfall on July 26 and August 2. Due to the rainfall during the observation, the UAS did not have the flight conditions, resulting in the missing of the temperature value of Lake 1. 
Both rainfall events were moderate rain and shower, which quickly formed runoff on the ground, and the cooling degree of the four land surfaces was close to $10^{\circ} \mathrm{C}$.
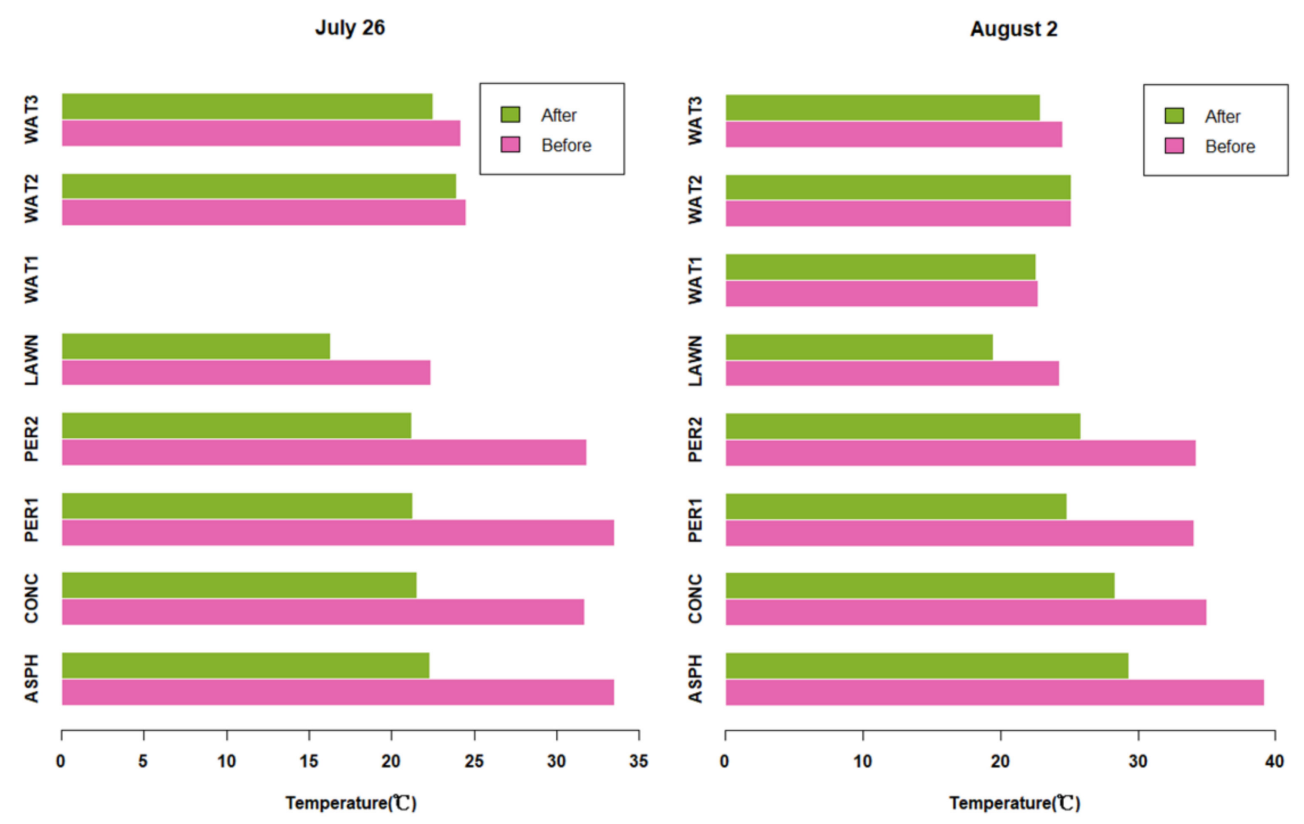

Figure 8. Changes in temperature before and after rainfall on different land surfaces on July 26 and August 2.

The research results show that the temperature of runoff rose rapidly within 4-9 min after rainfall and reached a thermal equilibrium state in about half an hour [27]. Therefore, after the rainwater temperature and the ground temperature reach the equilibrium state, the LST observed by meteorological observatories can be equivalent to the temperature of runoff.

By analyzing the LSWT changes of the three lakes before and after the rainfall, we found that the LSWT of Lake 1 and Lake 2 before and after the rainfall on August 2 changed (Tables S7-S13), which was caused by rainfall runoff. Figure 7 shows that the water temperature of the three lakes changes to different degrees before and after the rainfall. The measured temperature shows that the LSWT of the lake first decreases (3:13 p.m.-5:12 p.m.) and then rises (5:12 p.m.-7:14 p.m.) after rainfall. The depth of Lake 1 is twice as deep as that of Lake 3. It can be seen from Figure 8 that Lake 3 shows more obvious changes than Lake 1, so it can be concluded that shallower lakes react more quickly to thermal runoff. The LSWT rise rate of Lake 2 is not as high as that of Lake 1 and Lake 3, because the temperature of Lake 2 was measured using a fixed monitoring station. Before rainfall, the lake body absorbs heat radiation, and the temperature is relatively high; the temperature of rainwater at the beginning of rainfall is lower than the temperature of the lake body, which has a cooling effect on the lake body, while runoff is formed in the middle of rainfall, and the temperature of the runoff is higher than the temperature of the lake body, making the lake body temperature rise. We observed that the LSWT of Lake 2 at 3:13 p.m., 5:12 p.m., and 7:14 p.m. were all $25.1^{\circ} \mathrm{C}$ (Tables S8-S10); we speculated that this was caused by sensor errors. In order to verify the invariance of the water temperature of Lake 2, we obtained historical data from Lake 3 monitoring station to ensure that these data are in the same time series of August 2. Figure 9 shows that the surface temperature of Lake 3 showed a downward trend after rainfall. Handheld thermometers and UAS observed runoff leading to an increase in the lake's water temperature. Studies have shown that rainfall runoff has a warming effect on lake water. Our on-the-spot investigation found that the sensor measuring LSWT of Lake 2 sank to the bottom of the lake (Figure 10) and measured the temperature of the mud at the bottom of the lake instead of the water temperature. 

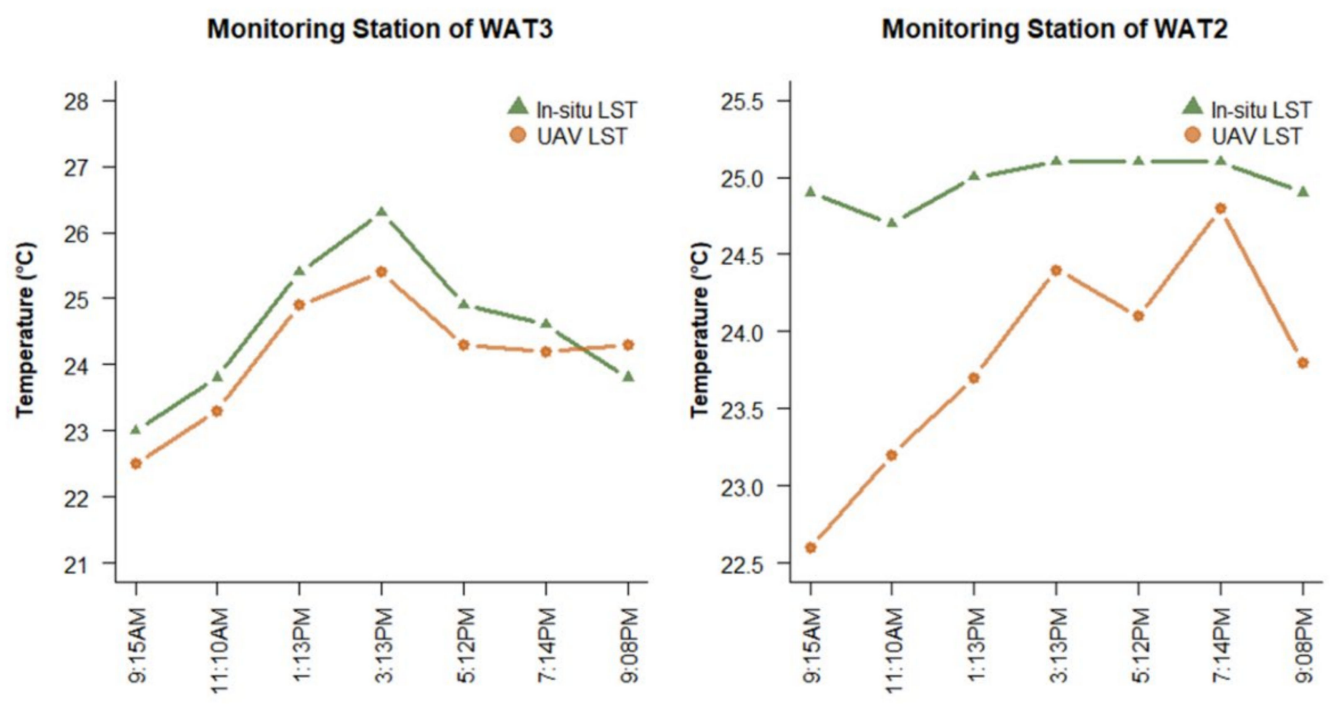

Figure 9. The impact of runoff on LSWT.

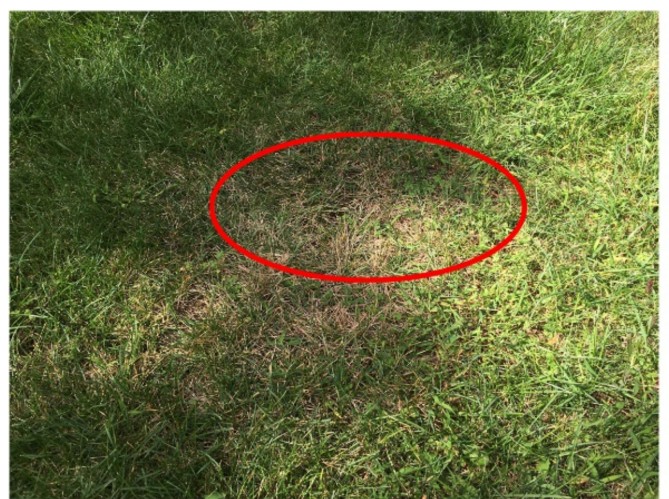

(a) withered lawn

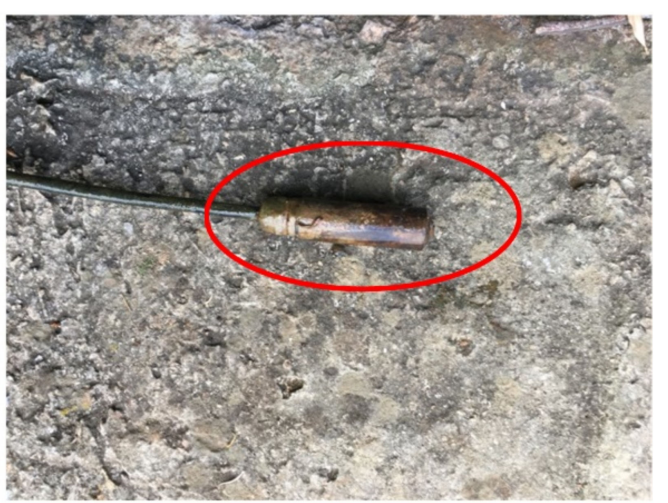

(b) Temperature sensor for Lake 2

Figure 10. Error of Lake 2 sensor.

The data in Tables S14 and S15 show that, based on the rainfall on July 26 and August 2 , the temperature rose slightly after $20 \mathrm{~min}$ of these two rainfalls. Both the surface lake monitoring stations and the LSWT monitored by UAS reported temperatures higher than the runoff temperature in the equilibrium state.

\subsection{Analysis of LST Observation Error}

Tables S16-S27 record the temperature data of each land surface from 9:00 a.m. on 24 July 2020 to 7:00 a.m. on 25 July 2020. This study used UAS to obtain the temperature data and in situ data of each land surface perform comparative analysis. For the observation data, we used the standard deviation reflecting the degree of dispersion of the observation data as the evaluation standard. The experimental data showed that the error value of the UAS observation of lawn temperature was relatively large. We found that the accuracy of lawn temperature observed by UAS was negatively correlated with solar radiation, that is, the weaker the solar radiation, the more accurate the lawn temperature observed by UAS; the stronger the solar radiation, the less accurate the lawn temperature observed by UAS. In our statistical data, the standard deviation of the temperatures of the lawn surface (July 24), the concrete surface, and Lake 2 observed in situ are all zero. These three land surfaces used fixed monitoring. For site measurement, due to the short observation period, the temperature data measured at the three sites are constant, so their standard deviation is zero, but the observation data is true and valid. 
The data in Table S16 shows that the land surface temperature differences between the UAS at 9:00 a.m. and observed in situ are relatively small. Based on UAS and handheld thermometer, the error value of lawn temperature is $3.6^{\circ} \mathrm{C}$, the error value of concrete surface temperature is $1^{\circ} \mathrm{C}$, and the error value of asphalt surface temperature is $0.04{ }^{\circ} \mathrm{C}$. Obviously, the lawn error value is larger, and the error value of other land surfaces is smaller. Based on the site measurement, the LSWT of Lake 1 and Lake 3 were overestimated $1.3{ }^{\circ} \mathrm{C}$ and $2{ }^{\circ} \mathrm{C}$ by UAS, while the LSWT of Lake 2 was the same. In summary, the observation results of UAS and in situ show a high degree of consistency. The data in Table S17 shows that the temperature difference of the lawn surface at around 10:58 a.m. based on UAS and the in situ observation data reached $8.6^{\circ} \mathrm{C}$ and above. UAS seriously overestimated the temperature of the lawn surface. The study of Song and Park [37] pointed out that, for vegetation, the LSTs were significantly different depending on the measurement points, because vegetation and non-vegetation areas were mixed, or the absorption of solar radiation varied depending on the leaf direction. The lawn area of this study is located next to a school building, and there are some street trees beside the lawn. Based on related studies, it is shown that the two factors of buildings and woods cause the high inconsistency of the lawn observation data. In this study, the lawn was affected by these two factors, which caused large errors in the observation of UAS. It is necessary for us to reduce discrepancies by continuously protecting on-site measurement data. The data in Table S18 shows that the inconsistency between the UAS image and the in situ observation temperature at around 1:21 p.m. is higher than that of the previous two observations. In particular, the lawn is overestimated by UAS by $12.5^{\circ} \mathrm{C}$, and Lake 2 has the highest consistency; the difference is only $1^{\circ} \mathrm{C}$. The data in Table S19 shows that, based on the two observation methods, in addition to the large temperature difference $\left(12.5^{\circ} \mathrm{C}\right)$ on the lawn surface affected by the building, the temperature difference of the asphalt surface also reached $5.8^{\circ} \mathrm{C}$. This is because UAS images are based on thermal radiation, and when the clouds block the solar radiation, the solar radiation received by the UAS camera decreases. The handheld thermometer is very close to the ground and is not affected by solar radiation. Therefore, UAS underestimated the asphalt surface temperature. In the observations of three small lakes, the LSWT of Lake 2 always maintained a high consistency. As time passes, when the solar radiation decreases significantly, the lawn research area is affected by both solar radiation and buildings. Tables S20 and S21 show that the inconsistency of the lawn surface temperature is significantly reduced, and in Tables S22-S27, it is finally constantly below $2{ }^{\circ} \mathrm{C}$. There is no solar radiation at night, so the ground receives less solar radiation. The main factor that affects the LSTs is wind. The surface shows a stable heat exchange. The temperature difference of various land surfaces based on the two observation methods of UAS and in situ measurement is very small $\left(0.1-2{ }^{\circ} \mathrm{C}\right)$. Because the specific heat capacity of the water body is larger than other land surfaces, the data at 5:16 a.m. and 7:16 a.m. (Tables S26 and S27) show that the water temperature was higher than that of lawn and asphalt pavement. This verifies the previous research and the need to build more park reservoirs conducive to alleviating the urban heat island effect.

\subsection{Discussion on the Possibility of UAS Carrying out Surface Thermal Runoff Pollution}

Tables S28 and S29 record the data under the rainfall conditions from 4:00 p.m. to 7:00 p.m. on 26 July 2020. The data shows that the temperature difference of the land surface of the lawn measured by the two observation methods before rainfall was $3.8^{\circ} \mathrm{C}$, and for the other land surfaces, the temperature difference was small; after the rainfall stopped, the temperature difference between the pervious brick surface and the concrete surface measured by the two observation methods doubled. This is because the UAS lens is far away from the ground during measuring, and the lens receives the solar radiation reflected from the ground. After the rain, the temperature was lower and the air humidity was higher, which caused the heat radiation to attenuate during the transmission process. In contrast, the in situ observation was closer to the ground and received the solar radiation reflected by the ground at a closer distance. This study carried out seven consecutive 
observations on rainfall from 9:00 a.m. to 9:00 p.m. on 2 August 2020. The data in Table S7 shows that concrete and asphalt are the two land surfaces with the fastest temperature rises in the study area on a sunny day. The similarity is consistent with the previous two observations. The data in Table $\mathrm{S} 8$ shows the same conclusion as the previous rainfall event. Before the rainfall, the influx of clouds blocked part of the solar radiation. UAS calculates the surface temperature based on the amount of heat radiation received by the lens, which resulted in a large error (about $3.0^{\circ} \mathrm{C}$ ) in the temperature of the asphalt land surface before and after the rainfall event. The data in Table S11 show that UAS showed a small error after rainfall, while the error of each observation on the land surface of the lawn was large. In this observation, UAS showed good accuracy, indicating that UAS equipped with thermal infrared lenses can be used in the observation and research of urban surface temperature. Figure 11 shows the linear regression analysis results of the three-day observation data of in situ LSTs and UAS LSTs.

(a)
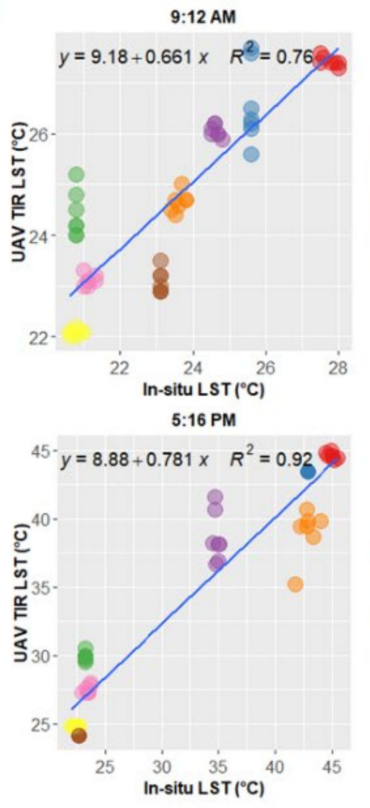

1:20 AM

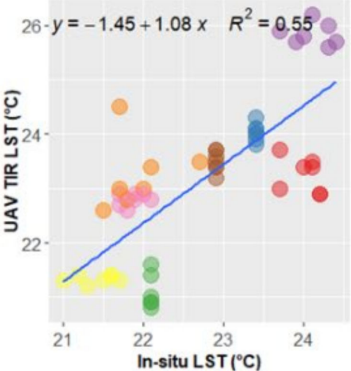

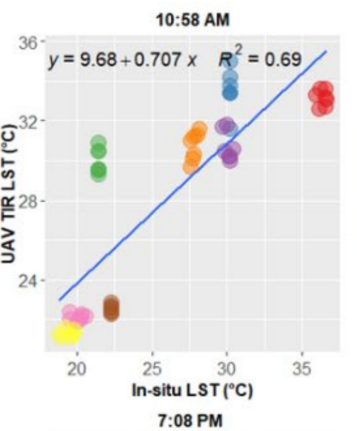
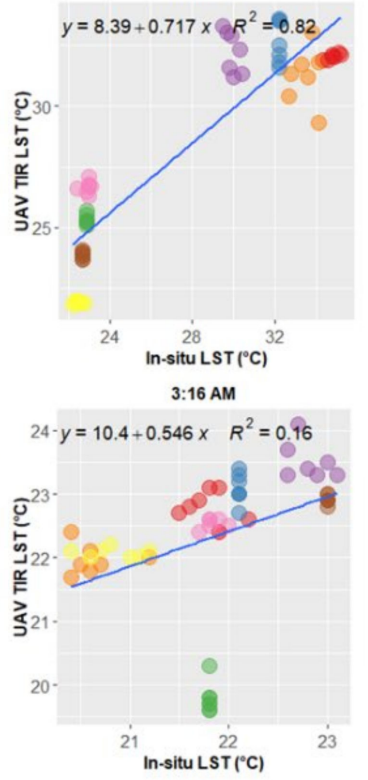
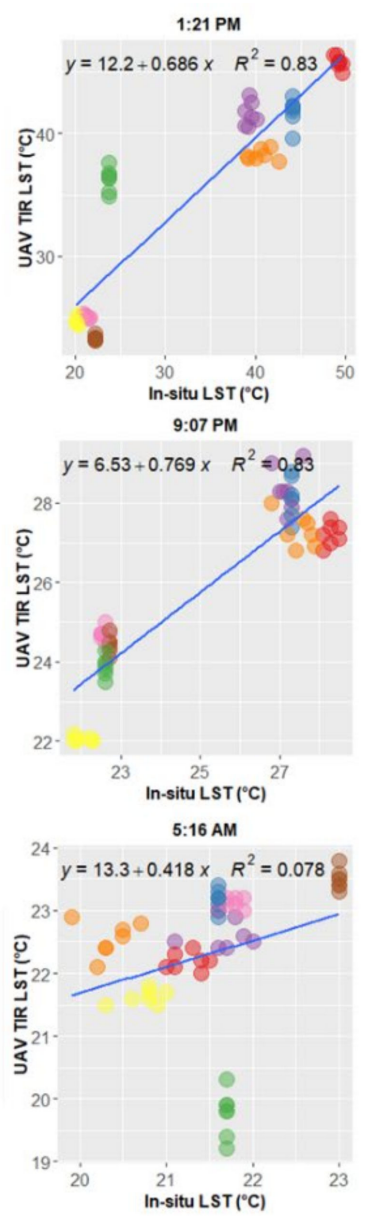
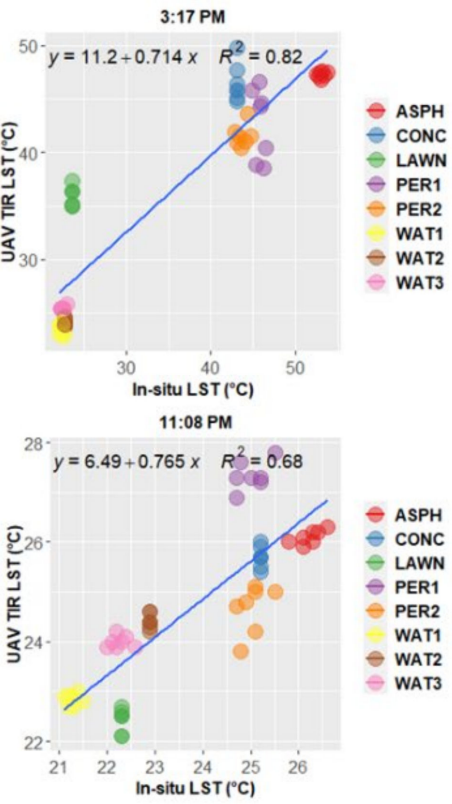

ASPH

CONC

LAWN

- PER1

- PER2

WAT1

WAT3

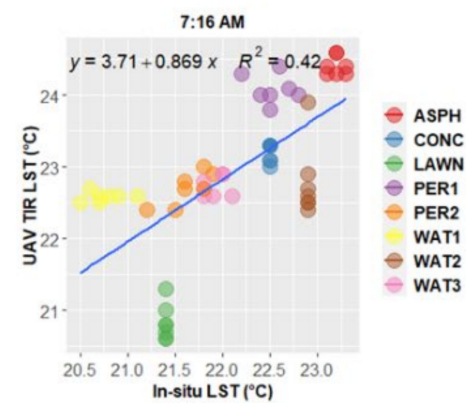

Figure 11. Cont. 

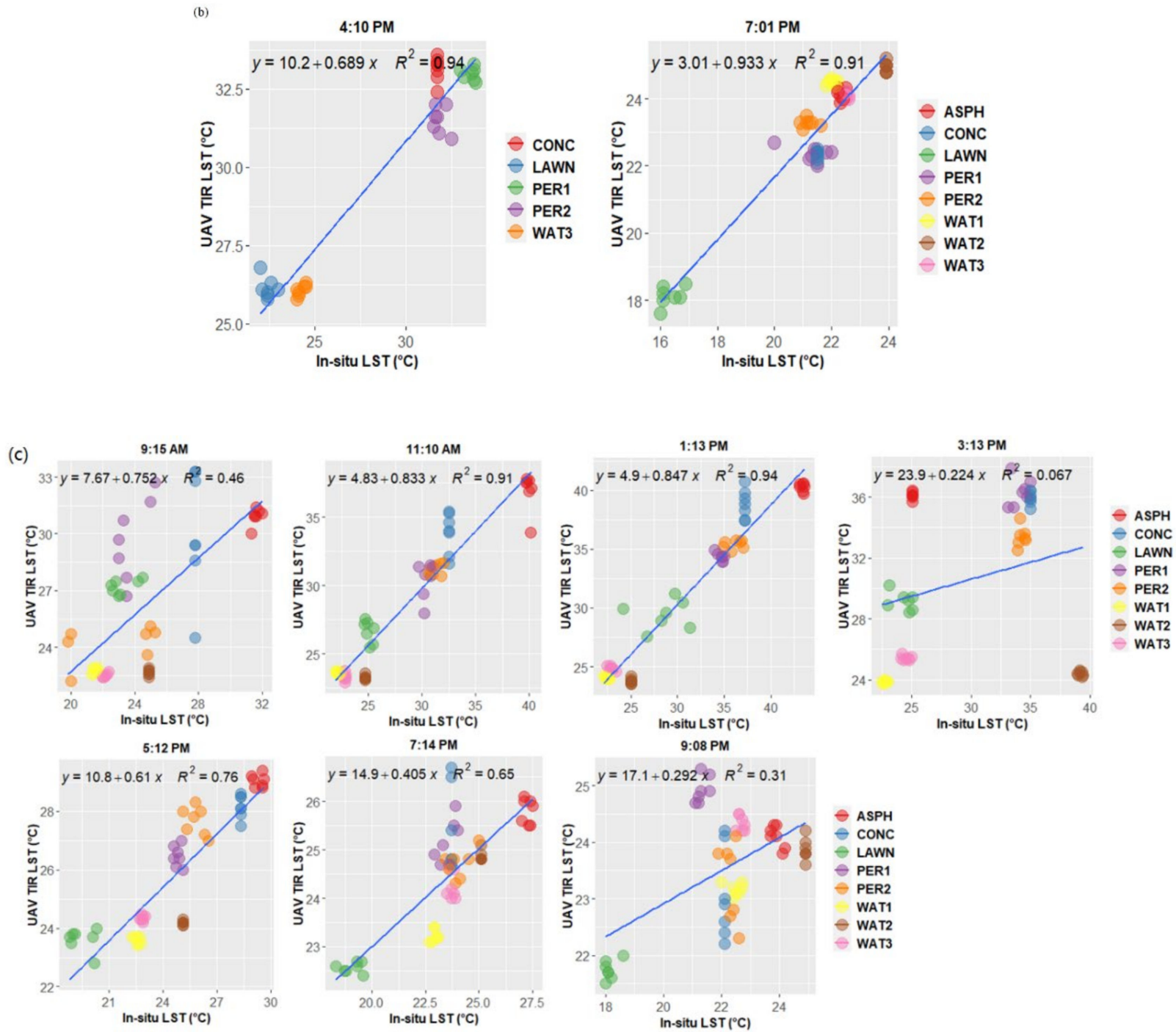

Figure 11. Linear regression results of UAS and in situ observations for different land cover types. (a) July 24 . (b) July 26. (c) August 2 .

Figure 11a shows that, based on UAS and in situ observation, the goodness of fit is relatively high in the 9:12 a.m.-11:08 p.m. time period. The value of $R^{\wedge} 2$ is between 0.68 and 0.92 ; then, $R^{\wedge} 2$ begins to decline to 0.42 . Because the UAS lens is based on the received thermal radiation imaging, the solar radiation intensity is high in the daytime, resulting in the gradual decline of $\mathrm{R}^{\wedge} 2$ at night, which eventually leads to the low fitting degree of 1:20 a.m. $-7: 16$ a.m. $\left(R^{\wedge} 2=0.078\right)$. These slopes indicate that the increment of UAS LST is smaller than that of in situ LST. Figure $11 \mathrm{~b}$ fits the observation data before and after the rainfall on July 26; the fitted results show a high consistency $\left(\mathrm{R}^{\wedge} 2=0.94\right)$, indicating that UAS can be used to observe the surface temperature before and after the daytime rainfall with high accuracy. Figure 11c fits the observation data on August 2. The rainfall event occurred between 3:59 p.m. and 4:40 p.m. and at 9:15 a.m. The two observation methods of each land surface had low consistency. Both 11:10 a.m. and 1:13 p.m. show a very high degree of fit $\left(\mathrm{R}^{\wedge} 2=0.94\right)$, which is the reason why much UAS research on earth observation chooses this time period for observation. Suddenly, a low degree of fit $\left(R^{\wedge} 2=0.067\right)$ appeared at the rainfall event at 3:13 p.m. After the rainfall stopped, the cloud cover was greatly reduced, and the accuracy of UAS observation was significantly improved (5:12 p.m., $R^{\wedge} 2=0.76$ ) The $R^{\wedge} 2$ value of 9:08 p.m. was low due to the influence of solar radiation. 
The data in Tables S30-S33 show the RMSE and MAE between in situ LSTs and UAS LSTs at different times on July 24 and August 2. At 9:12 a.m. on July 24, except for lawn, the RMSE and MAE of other different types of land covers were smaller; the LSWT of Lake 2 was the smallest $\left(\mathrm{RMSE}=0.21^{\circ} \mathrm{C}, \mathrm{MAE}=0.18^{\circ} \mathrm{C}\right)$, and the asphalt ground was also very small $\left(\mathrm{RMSE}=0.42, \mathrm{MAE}=0.35^{\circ} \mathrm{C}\right)$. The standard deviation of on-site LSTs is $0{ }^{\circ} \mathrm{C}$, which is less than the RMSE value, which shows the reliability of the analysis results. The study at 12:00 p.m. in the summer shows that the average RMSE of vegetation is the highest at $8.21{ }^{\circ} \mathrm{C}$ [37]. With the enhanced solar radiation intensity, the RMSE of different land surfaces also increased. This study the average RMSE value and the average MAE value during the day reached their maximums (respectively $4.33^{\circ} \mathrm{C}$ and $4.12^{\circ} \mathrm{C}$ ) at 3:17 p.m. The RMSE and MAE of pervious bricks started to increase at 9:12 a.m., reached the highest value (respectively $4.07{ }^{\circ} \mathrm{C}$ and $3.84^{\circ} \mathrm{C}$ ) at 5:16 p.m., and then decreased to about $1{ }^{\circ} \mathrm{C}$. Concrete and asphalt reached their maximum values (RMSE: $3.73^{\circ} \mathrm{C}$ and $5.84{ }^{\circ} \mathrm{C}$, MAE: $3.37^{\circ} \mathrm{C}$ and $5.84^{\circ} \mathrm{C}$ ) at 3:17 p.m. The RMSE and MAE of the three lakes showed different fluctuating trends. The RMSE and MAE of Lake 2 was the smallest (respectively $0.21^{\circ} \mathrm{C}$ and $\left.0.18^{\circ} \mathrm{C}\right)$. Observational data show that, at night (9:07 p.m.-7:16 a.m.), the average RMSE and MAE of all land surfaces were less than $1.19^{\circ} \mathrm{C}$ and $1.30{ }^{\circ} \mathrm{C}$, and the RMSE of the land surface of the lawn was also close to that of other land surfaces. It shows that UAS is suitable for the observation and research of the surface temperature at night.

\section{Discussions}

\subsection{Accuracy Verification of UAS}

This study compared UAS LSTs with in situ LSTs, and the accuracy of UAS LSTs was verified by linear regression and RMSE analysis. The study found that the accuracy of UAS LSTs is affected by weather conditions and time periods, such as solar radiation and cloud influx. Due to these factors, the RMSE between UAS LSTs and in situ LSTs varies between 1 and $5{ }^{\circ} \mathrm{C}$ (except for daytime lawn). Land surfaces such as pervious bricks, asphalt, and concrete exhibit high RMSE values. The linear regression analysis results show that the determination coefficient of the daytime model is close to 0.92 , which has a high goodness of fit.

This study shows that the accuracy of UAS observation LSTs depends on different land cover materials and different measurement time series, which is of great significance to the use of UAS thermal infrared images to study the change process of surface temperature. Kraaijenbrink et al. [38] used UAS to carry thermal infrared lenses to observe and map the surface temperature of the debris-covered glacier in the central Himalayas and compared UAS LST, Landsat8 images, and in situ LSTs of the glacier-covered area. UAS LST showed differences of $-1.4 \pm 1.8,11.0 \pm 5.2$, and $15.3 \pm 4.7^{\circ} \mathrm{C}$ during three flights. Kelly et al. [39], based on laboratory and on-site experiments, analyzed the accuracy of the thermal radiation FLIR Vue Pro 640 camera mounted on UAS. Although the accuracy was stable under laboratory conditions (about 0.5 degrees Celsius), due to the influence of environmental conditions, on-site experiments the accuracy was reduced to 5 degrees Celsius. The study on TIR satellite imagery showed that the difference between the satellite image LST and the on-site LST varies with time [37]. When the summer temperature is high, the difference may be greater than $10{ }^{\circ} \mathrm{C}$. Based on these research results, due to the accumulation of the earth's radiation energy released into the atmosphere in the space of dense buildings, UAS and in situ observations are very different.

\subsection{UAS Observation of Rainfall Runoff}

Above, we analyzed the accuracy of UAS. R^ 2 and RMSE showed different goodness of fit and error values in different observation time periods (Figure 11, Tables S28 and S31). We also explored the feasibility of UAS thermal infrared remote sensing technology to monitor rainfall runoff. For summer rainfall events, the data showed that surface runoff had a certain warming effect on the LSWT. In this study, after the runoff temperature and the air temperature reached equilibrium, the air temperature was equivalent to the runoff 
temperature. The advantage of UAS is the ability to collect distributed temperature data with high spatial resolution, which reflects small-scale changes in the urban environment. The research results show that UAS can be a good tool for evaluating the variability of other parameters of the urban environment, which are very important for environmental studies such as soil moisture, leaf area index, or impervious cover.

\section{Conclusions}

This study used UAS to carry thermal infrared lenses to obtain UAS LSTs on three dates (July 24, July 26, and August 2), and verified the accuracy of thermal infrared lenses. The research covered sunny and rainy days and daytime and nighttime. During rainfall events, we tried to use UAS to observe runoff temperature of the land surface of the city during the day and night and explore the feasibility of UAS to monitor and evaluate surface thermal runoff.

The study found that UAV overestimated the temperature of some types of land cover during the period from morning to noon on a sunny day. The temperature of the concrete surface was overestimated by $1^{\circ} \mathrm{C}$, and the temperature of the asphalt surface was different by $0.04{ }^{\circ} \mathrm{C}$. The LSWTs of Lake 1 and Lake 3 were overestimated by $1.3^{\circ} \mathrm{C}$ and $2{ }^{\circ} \mathrm{C}$, respectively. The temperature of Lake 2 remained the same. The temperature of the lawn surface was overestimated by UAS by $3.6^{\circ} \mathrm{C}$. Based on the small difference between UAS observations and in situ observations during the noontime period, many studies using UAS choose noon observations. From noon to afternoon, the influx of clouds and the sudden decrease in solar radiation received caused UAS to underestimate the LSTs. The lawn research area in this study was affected by woods and buildings, and the temperature difference observed between the two observation methods at noon was the largest $\left(12.5^{\circ} \mathrm{C}\right)$. At night, the temperature difference of the surface of the lawn was within $2{ }^{\circ} \mathrm{C}$. Both the standard deviation of the observation data and the temperature difference between the two observation methods were small $\left(0.1-2{ }^{\circ} \mathrm{C}\right)$. In a clear day, the linear regression analysis result is $0.69 \leq R^{\wedge} 2 \leq 0.92$, indicating that there is a high degree of consistency between UAS LSTs and in situ LSTs.

In the summer rainfall events, the lawn temperature difference between UAS and the in situ observation was $3.8^{\circ} \mathrm{C}$ before the rainfall; the temperature difference of other land surfaces was small. The two observation methods showed high consistency. The temperature difference between the two measurement methods doubled after the rainfall. Linear regression and RMSE analysis showed that there was a certain difference between the data observed by UAS and the on-site observation data in different weather. The water temperature of the three lakes changed to different degrees before and after the rainfall. The measured temperature showed that the LSWT of the lakes first decreased (3:13 p.m. $-5: 12$ p.m.) and then increased (5:12 p.m.-7:14 p.m.) after the rainfall. The lake body absorbs heat radiation before rainfall, resulting in a higher LSWT; at the beginning of rainfall, the temperature of rainwater is lower than the lake body temperature, which has a cooling effect on the lake body. In this study, the water temperature of Lake 3 dropped from $24.5^{\circ} \mathrm{C}$ to $22.9^{\circ} \mathrm{C}$ at the beginning of the rainfall. Runoff is formed in the middle of rainfall. Runoff temperature is higher than lake water temperature, which caused the LSWT of Lake 3 to rise from $22.9^{\circ} \mathrm{C}$ to $23.7^{\circ} \mathrm{C}$, so we concluded that the temperature of the lake had risen. However, the performance of the UAS camera we tested has some deviations that have not been successfully explained. During the flight, not measuring the camera sensor temperature was the main limitation of the camera's performance. We recommend buying a radiometric UAS camera with relatively high $\left( \pm 2{ }^{\circ} \mathrm{C}\right)$ accuracy, which is very worthwhile for applications where the absolute temperature difference is small. It is extremely important to effectively observe LST changes on a fine scale and to identify the thermal characteristics of various spatial factors distributed in urban areas. Small UAS equipped with thermal infrared lenses can be effectively used to observe the variability of different surface temperatures in cities. UAS can well make up for the low time and low spatial resolution of traditional satellite observations. This study used UAS 
to reveal the change of urban environmental temperature during daytime and nighttime and explored the feasibility of UAS to observe the LST during daytime and nighttime; we then monitored and analyzed day and night thermal runoff and explored the impact of thermal runoff on lake surface temperature changes. The study revealed the temperature changes of the surface types of hot runoff and the degree of pollution to urban lakes after rainfall. Due to the expansion of urbanization, impervious surfaces are the main cause of the UHI phenomenon. Current research on impervious surfaces is biased toward macroscopic research, while there is less research on the microscopic mechanisms. Through this study, we found the temperature changes of each surface type, clearly capturing the pollution degree of each surface cover type thermal runoff to urban lakes, and offered a more excellent choice for the urban surface cover type. This provides a solid foundation to alleviate the UHI phenomenon, an important basic condition for reducing urban lake pollution, and decision-making reference for the construction of beautiful cities.

Supplementary Materials: The following are available online at https:/ / www.mdpi.com/article / 10.3390 /su132011203/s1, Table S1. The acquisition time of the ten flights at July 24, Table S2. The acquisition time of the ten flights at July 26, Table S3. The acquisition time of the ten flights at August 2, Table S4. Equipment parameter table, Table S5. Emissivity values for each surface type, Table S6. Meteorological sensor parameters, Table S7. UAV TIR LSTs and in-situ LSTs by land cover type 9:15 AM at August 2, Table S8. UAV TIR LSTs and in-situ LSTs by land cover type 11:10 AM at August 2, Table S9. UAV TIR LSTs and in-situ LSTs by land cover type 1:13 PM at August 2, Table S10.UAV TIR LSTs and in-situ LSTs by land cover type 3:13 PM at August 2, Table S11. UAV TIR LSTs and in-situ LSTs by land cover type 5:12 PM at August 2, Table S12. UAV TIR LSTs and in-situ LSTs by land cover type 7:14 PM at August 2, Table S13. UAV TIR LSTs and in-situ LSTs by land cover type 9:08 PM at August 2, Table S14. Rain event on July 26, Table S15. Rain event on August 2, Table S16. UAV TIR LSTs and in-situ LSTs by land cover type 9:12 AM at July 24, Table S17. UAV TIR LSTs and in-situ LSTs by land cover type 10:58 AM at July 24, Table S18. UAV TIR LSTs and in-situ LSTs by land cover type 1:21 PM at July 24, Table S19. UAV TIR LSTs and in-situ LSTs by land cover type 3:17 PM at July 24, Table S20. UAV TIR LSTs and in-situ LSTs by land cover type 5:16 PM at July 24, Table S21. UAV TIR LSTs and in-situ LSTs by land cover type 7:08 PM at July 24, Table S22. UAV TIR LSTs and in-situ LSTs by land cover type 9:07 PM at July 24, Table S23. UAV TIR LSTs and in-situ LSTs by land cover type 11:08 PM at July 24, Table S24. UAV TIR LSTs and in-situ LSTs by land cover type 1:20 AM at July 25, Table S25. UAV TIR LSTs and in-situ LSTs by land cover type 3:16 AM at July 25, Table S26. UAV TIR LSTs and in-situ LSTs by land cover type 5:16 AM at July 25, Table S27. UAV TIR LSTs and in-situ LSTs by land cover type 7:16 AM at July 25, Table S28. UAV TIR LSTs and in-situ LSTs by land cover type 4:10 PM at July 26, Table S29. UAV TIR LSTs and in-situ LSTs by land cover type 7:01 PM at July 26, Table S30. RMSE between the in-situ LSTs and UAV TIR LSTs $\left({ }^{\circ} \mathrm{C}\right)$ at July 24 , Table S31. RMSE between the in-situ LSTs and UAV TIR LSTs $\left({ }^{\circ} \mathrm{C}\right)$ at August 2, Table S32. MAE between the in-situ LSTs and UAV TIR LSTs $\left({ }^{\circ} \mathrm{C}\right)$ at July 24, Table S33. MAE between the in-situ LSTs and UAV TIR LSTs $\left({ }^{\circ} \mathrm{C}\right)$ at August 2, Figure S1. Images UAV's of the first and second flight on July 24, Figure S2. Images UAV's of the third and fourth flight on July 24, Figure S3. Images UAV's of the fifth and sixth flight on July 24, Figure S4. Images UAV's of the seventh flight on July 24, Figure S5. Images UAV's of the eighth on July 24 and ninth flight July 25, Figure S6. Images UAV's of the tenth and eleventh flight on July 25, Figure S7. Images UAV's of the twelfth flight on July 25, Figure S8. Images UAV's of the first and second flight on July 26, Figure S9. Images UAV'S of the first and second flight on August 2, Figure S10. Images UAV's of the third and fourth flight on August 2, Figure S11. Images UAV's of the fifth and sixth flight on August 2, Figure S12. Images UAV's of the seventh flight on August 2, Figure S13. Images of night UAV on August 2.

Author Contributions: Conceptualized, designed and performed this research, Y.Z. (Yanhui Zhu) and K.Y.; analyzed the data and performed the experiments, Y.L.; drafted the manuscript, S.X. and Y.L.; edited the manuscript, C.S. and Y.X.; software, J.Z.; data collection, Y.Z. (Yang Zhang), M.G. and C.W. All authors have read and agreed to the published version of the manuscript.

Funding: This research was funded by National Natural Science Foundation of China (41761084), (41761037) and Yunnan Natural Science Foundation of China (2016FD020). 
Data Availability Statement: The data that support the findings of this study are available from the corresponding author upon reasonable request.

Conflicts of Interest: The founding sponsors had no role in the design of the study; in the collection, analyses, or interpretation of data; in the writing of the manuscript; or in the decision to publish the results.

\section{References}

1. Guan, X.; Wei, H.; Lu, S.; Dai, Q.; Su, H. Assessment on the urbanization strategy in China: Achievements, challenges and reflections. Habitat Int. 2018, 71, 97-109. [CrossRef]

2. Li, P.; Tian, R.; Xue, C.; Wu, J. Progress, opportunities, and key fields for groundwater quality research under the impacts of human activities in China with a special focus on western China. Environ. Sci. Pollut. Res. Int. 2017, 24, 13224. [CrossRef]

3. Sharma, K.; Gupta, S. Viscous dissipation and thermal radiation effects in MHD flow of Jeffrey nanofluid through impermeable surface with heat generation/absorption. Nonlinear Eng. 2017, 6, 153-166. [CrossRef]

4. Chen, W.-C.; Lin, C.-Y.; Chang, P.-L.; Sheng, Y.-F. Impact of the Urban Heat Island Effect on Precipitation over a Complex Geographic Environment in Northern Taiwan. J. Appl. Meteorol. Climatol. 2011, 50, 339-353. [CrossRef]

5. Imhoff, M.L.; Zhang, P.; Wolfe, R.E.; Bounoua, L. Remote sensing of the urban heat island effect across biomes in the continental USA. Remote Sens. Environ. 2010, 114, 504-513. [CrossRef]

6. Ferrari, A.; Kubilay, A.; Derome, D.; Carmeliet, J. The use of permeable and reflective pavements as a potential strategy for urban heat island mitigation. Urban Clim. 2020, 31, 100534. [CrossRef]

7. Zhou, D.; Bonafoni, S.; Zhang, L.; Wang, R. Remote sensing of the urban heat island effect in a highly populated urban agglomeration area in East China. Sci. Total Environ. 2018, 628, 415-429. [CrossRef] [PubMed]

8. Nogués-Bravo, D.; Araújo, M.B.; Errea, M.P.; Martínez-Rica, J.P. Exposure of global mountain systems to climate warming during the 21st Century. Glob. Environ. Chang. 2007, 17, 420-428. [CrossRef]

9. DeFries, R.S.; Rudel, T.; Uriarte, M.; Hansen, M. Deforestation driven by urban population growth and agricultural trade in the twenty-first century. Nat. Geosci. 2010, 3, 178-181. [CrossRef]

10. Li, H.; Zhou, Y.; Li, X.; Meng, L.; Wang, X.; Wu, S.; Sodoudi, S. A new method to quantify surface urban heat island intensity. Sci. Total Environ. 2018, 624, 262-272. [CrossRef]

11. Du, H.; Cai, W.; Xu, Y.; Wang, Z.; Wang, Y.; Cai, Y. Quantifying the cool island effects of urban green spaces using remote sensing Data. Urban For. Urban Green. 2017, 27, 24-31. [CrossRef]

12. Jia, D.; Jacinthe, P.; Zhou, H.; Xiang, X.; Zhao, B.; Wang, M.; Song, K. Monitoring of water surface temperature of Eurasian large lakes using MODIS land surface temperature product. Hydrol. Process. 2020, 34, 3582-3595. [CrossRef]

13. Gemitzi, A.; Dalampakis, P.; Falalakis, G. Detecting geothermal anomalies using Landsat 8 thermal infrared remotely sensed data. Int. J. Appl. Earth Obs. Geoinf. 2021, 96, 102283. [CrossRef]

14. Roy, P.; Guha, A.; Kumar, K.V. An approach of surface coal fire detection from ASTER and Landsat-8 thermal data: Jharia coal field, India. Int. J. Appl. Earth Obs. Geoinf. 2015, 39, 120-127. [CrossRef]

15. Vanhellemont, Q. Combined land surface emissivity and temperature estimation from Landsat 8 OLI and TIRS. ISPRS J. Photogramm. Remote Sens. 2020, 166, 390-402. [CrossRef]

16. Weng, Q.; Fu, P.; Gao, F. Generating daily land surface temperature at Landsat resolution by fusing Landsat and MODIS data. Remote Sens. Environ. 2014, 145, 55-67. [CrossRef]

17. Heimhuber, V.; Tulbure, M.; Broich, M. Addressing spatio-temporal resolution constraints in Landsat and MODIS-based mapping of large-scale floodplain inundation dynamics. Remote Sens. Environ. 2018, 211, 307-320. [CrossRef]

18. Cheng, K.; Chan, S.N.; Lee, J.H. Remote sensing of coastal algal blooms using unmanned aerial vehicles (UAVs). Mar. Pollut. Bull. 2020, 152, 110889. [CrossRef]

19. Du, M.; Noguchi, N.; Ito, A.; Shibuya, Y. Correlation analysis of vegetation indices based on multi-temporal satellite images and unmanned aerial vehicle images with wheat protein contents. Eng. Agric. Environ. Food 2019. [CrossRef]

20. Li, X.; Levin, N.; Xie, J.; Li, D. Monitoring hourly night-time light by an unmanned aerial vehicle and its implications to satellite remote sensing. Remote Sens. Environ. 2020, 247, 111942. [CrossRef]

21. Maes, W.H.; Steppe, K. Perspectives for Remote Sensing with Unmanned Aerial Vehicles in Precision Agriculture. Trends Plant. Sci. 2019, 24, 152-164. [CrossRef]

22. Naughton, J.; McDonald, W. Evaluating the Variability of Urban Land Surface Temperatures Using Drone Observations. Remote Sens. 2019, 11, 1722. [CrossRef]

23. Webster, C.; Westoby, M.; Rutter, N.; Jonas, T. Three-dimensional thermal characterization of forest canopies using UAV photogrammetry. Remote Sens. Environ. 2018, 209, 835-847. [CrossRef]

24. Silvestri, M.; Marotta, E.; Buongiorno, M.F.; Avvisati, G.; Belviso, P.; Bellucci Sessa, E.; Caputo, T.; Longo, V.; De Leo, V.; Teggi, S. Monitoring of Surface Temperature on Parco delle Biancane (Italian Geothermal Area) Using Optical Satellite Data, UAV and Field Campaigns. Remote Sens. 2020, 12, 2018. [CrossRef]

25. Herb, W.R.; Janke, B.; Mohseni, O.; Stefan, H.G. Thermal pollution of streams by runoff from paved surfaces. Hydrol. Process. 2008, 22, 987-999. [CrossRef] 
26. Zhou, F.; Xu, Y.; Chen, Y.; Xu, C.Y.; Gao, Y.; Du, J. Hydrological response to urbanization at different spatio-temporal scales simulated by coupling of CLUE-S and the SWAT model in the Yangtze River Delta region. J. Hydrol. 2013, 485, 113-125. [CrossRef]

27. Yi, L.; Li, Q.; Yang, K.; Xie, W.; Zhou, X.; Shang, C.; Xu, Y.; Zhang, Y.; Zhang, C. Thermodynamic analysis of air-ground and water-ground energy exchange process in urban space at micro scale. Sci. Total Environ. 2019, 694, 133612. [CrossRef] [PubMed]

28. Kim, K.; Thompson, A.M.; Botter, G. Modeling of thermal runoff response from an asphalt-paved plot in the framework of the mass response functions. Water Resour. Res. 2008, 44. [CrossRef]

29. Yang, K.; Yu, Z.; Luo, Y.; Zhou, X.; Shang, S. Spatial-Temporal Variation of Lake Surface Water Temperature and Its Driving Factors in Yunnan-Guizhou Plateau. Water Resour. Res. 2009. [CrossRef]

30. Yang, K.; Yu, Z.; Luo, Y. Analysis on driving factors of lake surface water temperature for major lakes in Yunnan-Guizhou Plateau. Water Res. 2020, 184, 116018. [CrossRef]

31. Jeppesen, E.; Kronvang, B.; Meerhoff, M.; Sondergaard, M.; Hansen, K.M.; Andersen, H.E.; Lauridsen, T.L.; Liboriussen, L.; Beklioglu, M.; Ozen, A.; et al. Climate change effects on runoff, catchment phosphorus loading and lake ecological state, and potential adaptations. J. Environ. Qual. 2009, 38, 1930-1941. [CrossRef] [PubMed]

32. Sabouri, F.; Gharabaghi, B.; Mahboubi, A.A.; McBean, E.A. Impervious surfaces and sewer pipe effects on stormwater runoff temperature. J. Hydrol. 2013, 502, 10-17. [CrossRef]

33. Yang, K.; Yu, Z.; Luo, Y.; Yang, Y.; Zhao, L.; Zhou, X. Spatial and temporal variations in the relationship between lake water surface temperatures and water quality-A case study of Dianchi Lake. Sci. Total Environ. 2018, 624, 859-871. [CrossRef]

34. Jinchen, T. 'One Belt and One Road': Connecting China and the world. Global Infrastructure Initiative Website. 2016. Available online: https://www.researchgate.net/profile/Myo_Myanmar/project/CHINA-INVASION-BUSINESS-IN-MYANMAR/ attachment/58f703501042bf25c0c9a281/AS:484743432151040@1492583248065/download/CHINA+ONE+BELT-ONE+ROAD+ PROJECT+AND+MYANMAR.pdf?context=ProjectUpdatesLog (accessed on 12 September 2021).

35. Luo, Y.; Zhao, Y.; Yang, K.; Chen, K.; Pan, M.; Zhou, X. Dianchi Lake watershed impervious surface area dynamics and their impact on lake water quality from 1988 to 2017. Environ. Sci. Pollut. Res. Int. 2018, 25, 29643-29653. [CrossRef]

36. Chiu, L.C.; Chang, T.S.; Chen, J.Y.; Chang, N.Y. Fast SIFT design for real-time visual feature extraction. IEEE Trans. Image Process. 2013, 22, 3158-3167. [CrossRef]

37. Song, B.; Park, K. Validation of ASTER Surface Temperature Data withIn SituMeasurements to Evaluate Heat Islands in Complex Urban Areas. Adv. Meteorol. 2014, 2014, 1-12. [CrossRef]

38. Kraaijenbrink, P.D.A.; Shea, J.M.; Litt, M.; Steiner, J.F.; Treichler, D.; Koch, I.; Immerzeel, W.W. Mapping Surface Temperatures on a Debris-Covered Glacier With an Unmanned Aerial Vehicle. Front. Earth Sci. 2018, 6, 64. [CrossRef]

39. Kelly, J.; Kljun, N.; Olsson, P.-O.; Mihai, L.; Liljeblad, B.; Weslien, P.; Klemedtsson, L.; Eklundh, L. Challenges and Best Practices for Deriving Temperature Data from an Uncalibrated UAV Thermal Infrared Camera. Remote Sens. 2019, 11, 567. [CrossRef] 